\title{
Effect of carrier gas pressure on structural, optical and photovoltaic properties of tin sulphide thin films prepared by nebulizer spray pyrolysis method
}

\author{
A M S ARULANANTHAM ${ }^{1, *}$, S VALANARASU ${ }^{1}, \mathrm{~K}^{\text {JEYADHEEPAN }}{ }^{2}$ and A KATHALINGAM ${ }^{3}$ \\ ${ }^{1} \mathrm{PG}$ and Research Department of Physics, Arul Anandar College, Karumathur 625514, India \\ ${ }^{2}$ Multifunctional Materials and Devices Lab, Anusandhan Kendra - II, School of Electrical and Electronics Engineering, \\ SASTRA University, Tirumalaisamudram, Thanjavur 613 401, India \\ ${ }^{3}$ Millimeter-Wave Innovation Technology Research Center (MINT), Dongguk University Seoul, Seoul 04620, \\ Republic of Korea \\ *Author for correspondence (amsarul@gmail.com)
}

MS received 3 May 2018; accepted 24 September 2018; published online 27 March 2019

\begin{abstract}
Tin sulphide $(\mathrm{SnS})$ thin films deposited using nebulizer spray pyrolysis technique by changing pressure $(0.1$, $0.15,0.2$ and 0.25 Pascal) at $350^{\circ} \mathrm{C}$ and their characterization are reported. The influence of carrier gas pressure on structural, morphological, optical and electrical properties of the film are determined using X-ray diffraction (XRD), energy-dispersive $\mathrm{X}$-ray, atomic force microscopy, UV-Vis spectrophotometry and Hall effect measurement. Structural parameters such as pole density, orientation factor, crystallite size, micro strain and dislocation density were analysed using XRD data. The scanning electron microscopy studies display superior morphology and surface roughness of the films which were found to increase with pressure. Optical studies on the films revealed a variation in band gap from 1.78 to $1.66 \mathrm{eV}$ for were the raise of pressure from 0.1 to $0.2 \mathrm{~Pa}$. A single strong emission peak at about $825 \mathrm{~nm}$ is observed in photoluminescence spectra with enhanced intensity which may be attributed to near band edge emission. Grown SnS thin film exhibits p-type conductivity, which was confirmed from the Hall effect measurement. The low resistivity and higher carrier concentration are found to be $0.235 \Omega \mathrm{cm}$ and $5.04 \times 10^{18} \mathrm{~cm}^{-3}$, respectively. These properties were then correlated with the deposition parameters. Furthermore, to study the photovoltaic properties of $\mathrm{SnS}$ thin films, a heterojunction solar cell FTO/n-CdS/p-SnS/Al was fabricated showing conversion efficiency of $0.16 \%$.
\end{abstract}

Keywords. Nebulizer spray; carrier gas pressure; SEM/AFM; Hall measurements; solar cell efficiency.

\section{Introduction}

Tin sulphide (SnS) belonging to group IV-VI semiconducting chalcogenides considered as one of the most successful materials for solar photovoltaic (PV) and optoelectronic applications [1]. Albeit its excellent achievements, some problems remain to be solved. There are a lot of concerns of cadmium, gallium and indium-based devices on environmental suitability, availability and toxicity [2]. Compared to other inorganic compound semiconductors, $\mathrm{SnS}$ is more suitable for solar cell and other applications. SnS possesses reasonable optical and electrical properties, such as transparency and narrow band gap [3]. It is used as an absorber layer for PV cells $[3,4]$. The theoretical study also shows that a conversion efficiency of $25 \%$ can be obtained by using $\mathrm{SnS}$ in solar cells. $\mathrm{SnS}$ is an advanced material because it has high potential in manufacturing devices [5]. SnS has some characteristics, such as (i) high absorption coefficient near the fundamental absorption edge as that of CdTe, (ii) band gap lies in between GaAs $(1.43 \mathrm{eV})$ and $\mathrm{Si}(1.12 \mathrm{eV})$, (iii) non-hazardous in nature and (iv) both the component materials tin and sulphur are plentiful and not expensive [6]. This nature of $\mathrm{SnS}$ makes it a suitable material for thin film solar cell with $\mathrm{CdS}[6,7]$ and $\mathrm{ZnO}[8]$ as window material with a broad band gap. The p-type conductivity of $\mathrm{SnS}$ is due to the formation of tin vacancies which are shallow acceptors. The S-vacancy on Sn acts as donor which plays a considerable role in $\mathrm{PV}$ properties [9].

Many different methods have been utilized for the fabrication of SnS layers such as atmospheric pressure chemical vapour deposition [10], chemical bath deposition [11], spray pyrolysis [12], electrodeposition [13], thermal evaporation [14], electron beam evaporation [15], d.c. magnetron sputtering [16], atomic layer deposition [17] and successive ionic layer adsorption and reaction $[1,18]$. Knowledge about the material and well known device designs pave the way to $\mathrm{SnS}$ related solar devices with efficiency $>10 \%$ [8]. From our literature survey, we did not find any reports on the influence of carrier gas pressure on the structural, physical, optical, electrical and PV properties of SnS films coated on glass substrate by the nebulizer spray pyrolysis (NSP) method. In this work, we systematically investigated the influence of carrier gas pressure on the structural, physical, optical, 
electrical and PV properties of SnS films grown by the NSP method.

\section{Experimental}

Tin sulphide $(\mathrm{SnS})$ thin films were deposited on glass substrates using the NSP technique. The precursor solution consisted of tin(II) chloride $\left(\mathrm{SnCl}_{2}\right)$ and thiourea $\left(\mathrm{CS}\left(\mathrm{NH}_{2}\right)_{2}\right)$. A 1:1 molar ratio of tin and thiourea of each $0.1 \mathrm{M}$ were dissolved in $10 \mathrm{ml}$ of de-ionized water. A few drops of $\mathrm{HCl}$ were added for complete dissolution of the precursor. Compressed air was used as a gas carrier in the nebulizer spray to produce fumes. The precursor solution was sprayed onto the glass substrates at different pressure rates as $0.1,0.15,0.2$ and $0.25 \mathrm{~Pa}$, to produce highly crystalline, optical quality and low resistive SnS thin films. All other deposition parameters, such as substrate temperature $\left(350^{\circ} \mathrm{C}\right)$, the nozzle to substrate distance $(50 \mathrm{~mm})$, precursor concentration $(1: 1 \mathrm{M})$ and the volume of precursor solution $(10 \mathrm{ml})$ were optimized and kept constant. The nebulizer spray gun was equipped with a microprocessor controlled stepper motor system which moved it in the $x-y$ direction to attain much uniformity of the films. After deposition, the films were permitted to cool down to room temperature and then the films were removed from the heater.

\subsection{Characterization}

Deposited SnS films were characterized to investigate the structural, surface (morphological and compositional analysis), optical and electrical properties. The thickness of the sample was analysed using a Stylus profilometer (Mitutoyo SJ-301). The structural analyses of the films were performed using X-ray diffractometer (PAN analytical X'Pert PRO) with $\mathrm{CuK} \alpha_{1}$ radiation in the Bragg angle range of $10-80^{\circ}$. The compound formation was further confirmed using Raman analysis (STR $500 \mathrm{~mm}$ focal length laser Raman spectrometer). Morphology of the films was analysed using a scanning electron microscope (SEM) (EVO 18 ZEISS) and EDAX spectra were used to analyse the elements present in the film. A double-beam UV-Vis-NIR spectrophotometer (Lambda Perkin Elmer) was used in the range of 300-1100 nm, to measure the transmittance and absorption spectra of the films and to calculate the optical band gap of the films. The photoluminescence (PL) spectra of the films were studied using a PerkinElmer Ls-55 spectrofluorometer. A Keithley interactive digital source-meter (model-2450) was used for the Hall measurements and $I-V$ characterization of $\mathrm{SnS}$ thin films.

\section{Results and discussion}

\subsection{Structural studies}

3.1a XRD analysis: The thickness of the deposited films was measured using Stylus profilometer which showed an increase in thickness from 740 to $850 \mathrm{~nm}$ for the increase of carrier gas pressure from 0.1 to $0.2 \mathrm{~Pa}$. The crystalline quality of the films prepared using different carrier gas pressures was characterized by X-ray diffraction (XRD) analysis, and the patterns are shown in figure 1 . The diffraction peaks presented in the patterns show that the films exhibit preferential orientation and is in agreement with JCPDS card no. 65-2610 of SnS. It also shows that the fabricated films possess an orthorhombic structure with polycrystalline nature and strongly oriented along the (210) and (111) directions. The other diffraction peaks correspond to (301), (211), (311), (202), (610) and (222) orientations. These structural data are also in agreement with the $\mathrm{SnS}$ films prepared by spray technique [19]. The intensity of the peaks is increased with the increase in carrier gas pressure from 0.1 to $0.2 \mathrm{~Pa}$. It indicates that there is an improvement in layer orientation and crystalline quality. The higher peak intensity at $0.2 \mathrm{~Pa}$ of carrier gas pressure indicates the improved crystalline quality of the films [20]. The increased thickness and crystalline size may be attributed to the increase in the number of particles reaching the substrate inside the tubular furnace, which leads to the enhanced chemical reaction rate in the droplet. However, on further increase of pressure from 0.2 to $0.25 \mathrm{~Pa}$, the intensity of the peaks decreased, which indicates that the crystalline quality of the film is slightly decreased. These results indicate that increase of carrier gas pressure degrades the crystalline quality of the film which may be attributed to high pressure at which the solute particles bounce and scatter instead of being adsorbed on the surface [21]. Similarly, the grain size is also controlled by the early nucleation of the island which depends on the pressure rate. Therefore, on optimal carrier gas pressure might be useful for the formation of nuclei or the amalgamation of large number of nuclei to form large grain size [22].

The texture value of deposited $\mathrm{SnS}$ films was estimated by the Harris method [23,24]. The pole density $\left(P_{i}\right)$ was calculated by using the following equation [23]:

$$
P_{i}=\frac{\left(I_{i} / I_{o i}\right)}{(1 / N) \sum_{i=1}^{N} I_{i} / I_{o i}},
$$

where $I_{i}$ and $I_{o i}$ are the total intensities of diffraction and reference peaks of the film, respectively, and $N$ is the number of peaks present in the XRD pattern.

Orientation factor was calculated using the equation below [24]:

$$
f=\sqrt{\frac{1}{N} \sum_{i-1}^{N}\left(P_{i}-1\right)} .
$$

Calculation by inverse pole figures method was done using the plane (210) for texture growth analysis of the SnS films. The texture growth along the (210) plane direction was well matched with the earlier reports of SnS thin films [23,25]. The texture growth of the $\mathrm{SnS}$ film showed high value and is 


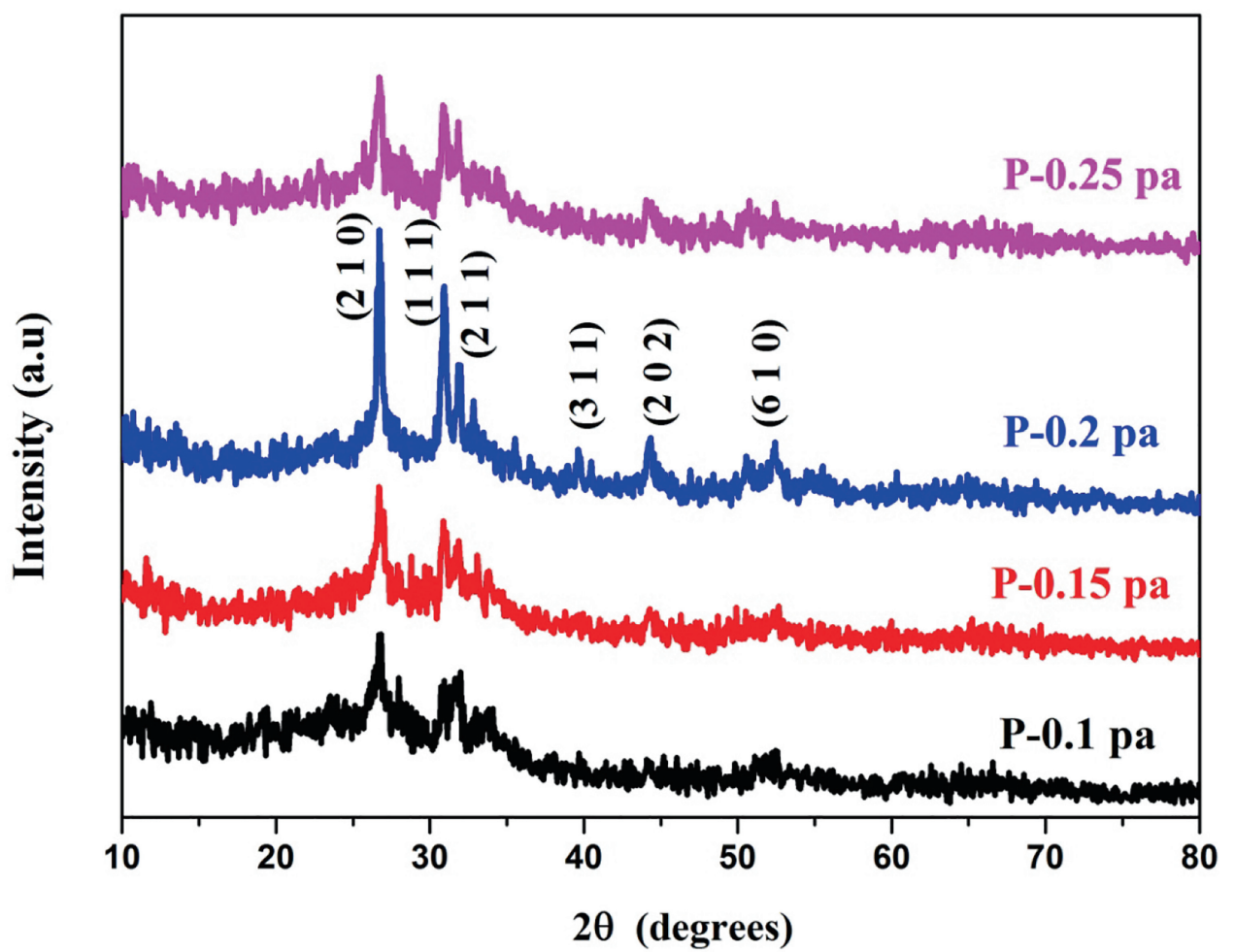

Figure 1. XRD pattern of $\mathrm{SnS}$ thin films prepared at different pressures.

Table 1. Results of the calculation for the texture pole density $\left(P_{i}\right)$ and orientation factor $(f)$.

\begin{tabular}{lccc}
\hline Pressure $(\mathrm{Pa})$ & $h k l$ & Pole density $\left(P_{i}\right)$ & Orientation factor $(f)($ a.u. $)$ \\
\hline 0.1 & 210 & 1.05 & 0.032 \\
0.15 & 210 & 1.12 & 0.069 \\
0.2 & 210 & 1.78 & 0.45 \\
0.25 & 210 & 1.27 & 0.15 \\
\hline
\end{tabular}

given in table 1. Film deposited at 0.2 Pa pressure rate shows orientation factor of 0.45 . For a further increase of pressure by $0.25 \mathrm{~Pa}$, the growth texture of the layers decreased slightly to 0.15 and this trend of change is similar to the report by Voznyi et al [23].

To calculate the crystallite size $(D)$ of $\mathrm{SnS}$ film the XRD profile information was used in Scherrer equation below [20]:

$$
D=\frac{k \lambda}{\beta \cos \theta}
$$

where $k$ is a constant equal to $0.94, \beta$ full width at half maximum value of XRD peak, $\lambda$ the wavelength of X-ray $(1.5406 \AA)$ and $\theta$ the Bragg's angle. This showed an increase of crystallite size from 22 to $33 \mathrm{~nm}$ for the increase in pressure rate from 0.1 to $0.2 \mathrm{~Pa}$, respectively. On further increase in pressure rate from 0.2 to $0.25 \mathrm{~Pa}$, the crystallite size decreased. However, the high pressure-induced disturbances can also liberate the particles from the substrate surface. So, at higher pressure, this desorption is increased causing decreased number of crystallites and also thickness of the film. This decrease of crystallite size with pressure increase is also witnessed by XRD studies.

The microstrain $(\varepsilon)$ of the $\mathrm{SnS}$ film was estimated using the below equation [22]:

$$
\varepsilon=\frac{\beta \cos \theta}{4} \text {. }
$$

The microstrain $(\varepsilon)$ values of the coated films decreased gradually on increasing pressure from 0.1 to $0.2 \mathrm{~Pa}$ as shown in table 2 . This enhances the crystallinity due to regular arrangements of atoms in the crystal lattice at $0.2 \mathrm{~Pa}$ pressure rate. On further increasing the pressure rate from 0.2 to $0.25 \mathrm{~Pa}$, the strain increased. This result attributes the adverse effect of pressure on nucleation leading to poor crystallinity of the film for $0.25 \mathrm{~Pa}$ pressure rate [26]. 
Table 2. Structural parameters of deposited $\mathrm{SnS}$ thin films at various pressures.

\begin{tabular}{lccc}
\hline Pressure $(\mathrm{Pa})$ & Thickness $(\mathrm{nm})$ & Crystallite size $(\mathrm{nm})$ & Strain $\left(\varepsilon \times 10^{-3}\right.$ lines $\left.^{-2} \mathrm{~m}^{-4}\right)$ \\
\hline 0.1 & 740 & 22 & 6.6 \\
0.15 & 790 & 27 & 5.4 \\
0.2 & 850 & 33 & 4.4 \\
0.25 & 830 & 28 & 5.2 \\
\hline
\end{tabular}

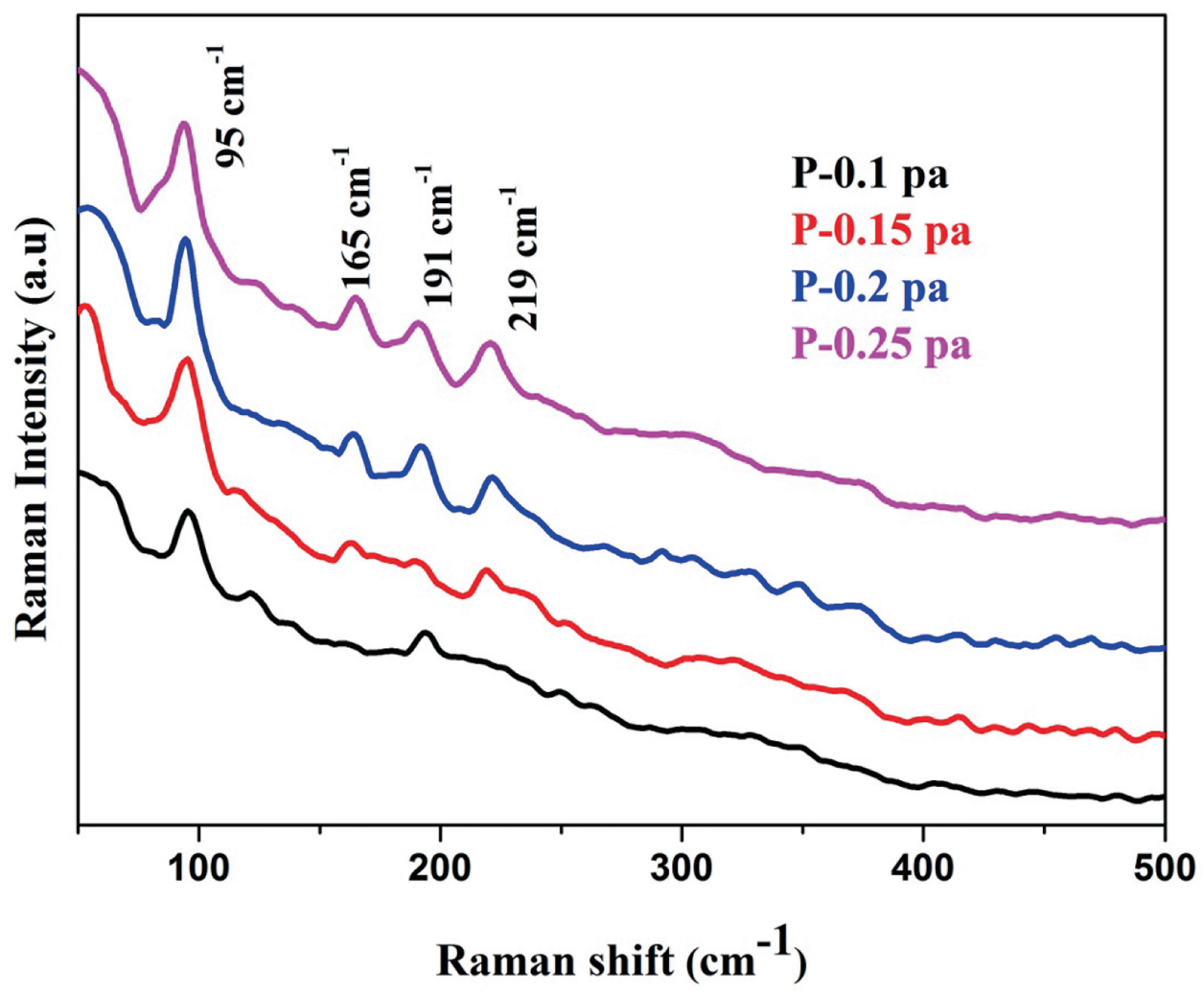

Figure 2. Raman spectra of $\mathrm{SnS}$ thin films at different pressures.

3.1b Raman analysis: Raman spectra of $\mathrm{SnS}$ films obtained in the wave number range of $50-500 \mathrm{~cm}^{-1}$ at room temperature are shown in figure 2. All the films exhibited Raman peaks corresponding to SnS. The predominant Raman longitudinal optical (LO) and transverse optical (TO) modes are in the frequency region of $50-500 \mathrm{~cm}^{-1}$. The peaks observed at 95, 165, 191 and $219 \mathrm{~cm}^{-1}$ are linked to a variety of optical phonon modes of the SnS phase, which is in harmony with the reported data by Sinsermsuksakul et al [27]. The peak presented at 191 and $219 \mathrm{~cm}^{-1}$ are assigned to the LO $A_{g}$ mode, whereas the other peak $95 \mathrm{~cm}^{-1}$ is assigned to the TO $\mathrm{A}_{\mathrm{g}}$ mode. These $\mathrm{A}_{\mathrm{g}}(\mathrm{TO})$ and $\mathrm{A}_{\mathrm{g}}(\mathrm{LO})$ modes are nearer to the Raman mode reported by Reddy et al [28]. The observed $\mathrm{B}_{2 \mathrm{~g}}$ optical Raman modes at $165 \mathrm{~cm}^{-1}$ is attributed to the $\mathrm{SnS}$ phase, which matches with the Raman data reported by Srinivasa Reddy et al [29]. There are no bands corresponding to the secondary phases of $\mathrm{Sn}$ and $\mathrm{S}$ observed in the spectrum. This result confirms that the films grown at various pressures are pure without any impurities such as $\mathrm{SnS}_{2}$ and $\mathrm{Sn}_{2} \mathrm{~S}_{3}$. Thus, the Raman studies along with XRD confirm the single phase of SnS films fabricated by the NSP technique.

\subsection{Surface analysis}

3.2a SEM and composition analyses: SEM micrographs for $\mathrm{SnS}$ thin films are shown in figure $3 \mathrm{a}-\mathrm{d}$. It shows that the films are uniform without any cracks and pinholes. The surface morphology was found to be affected by carrier gas pressure. The films are densely packed with crystallites and grow with different sizes in the same directions. From figure $3 a$ and $b$, it is clearly seen that the film consists of fine-grains with nanometre-sized particles. Figure 3a shows the samples prepared at 0.1- Pa formed polycrystalline needles. This type of formation was also 

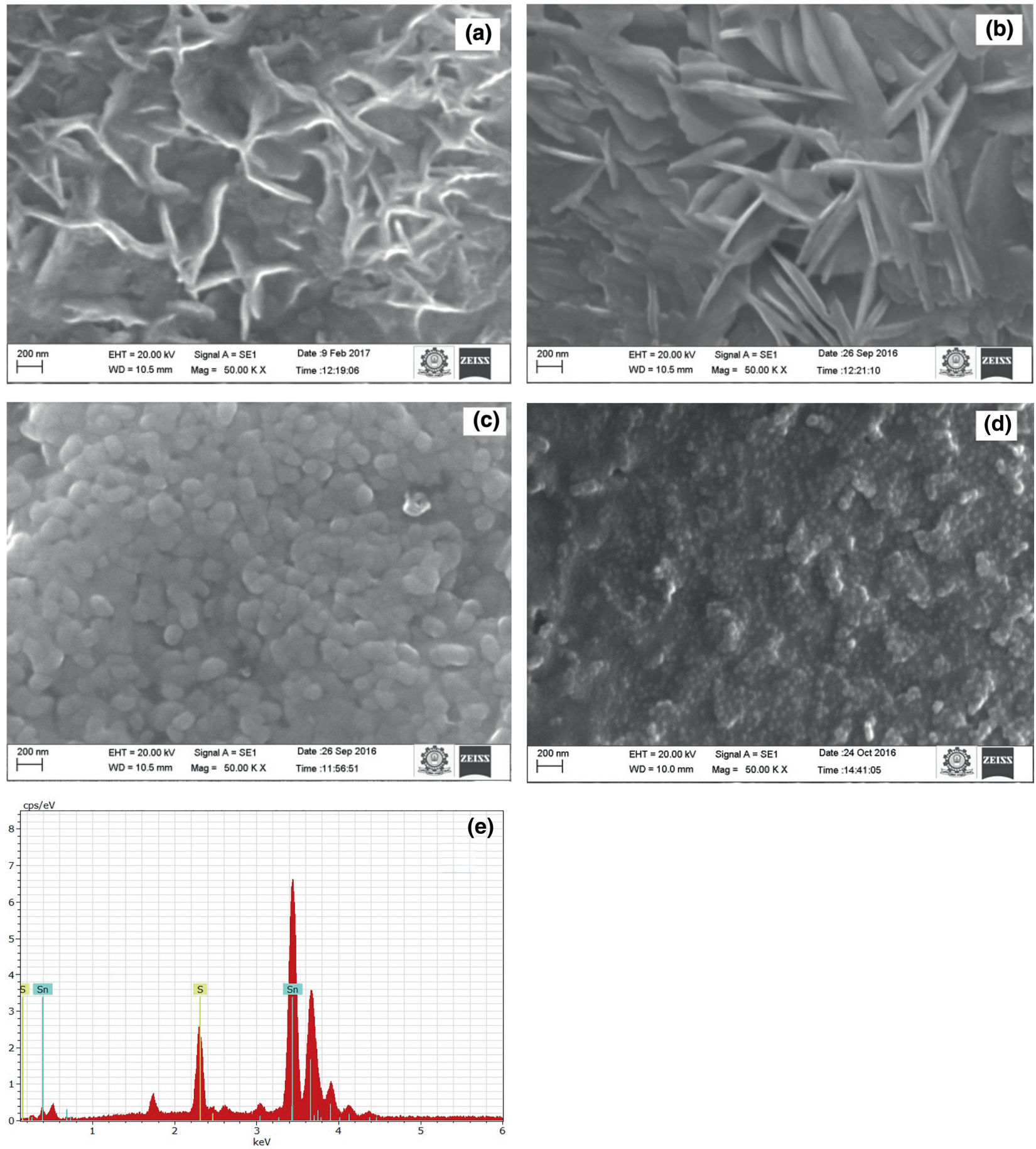

Figure 3. SEM image and EDAX spectrum of SnS thin films prepared at different pressures: (a) 0.1, (b) 0.15 , (c) 0.2 , (d) $0.25 \mathrm{~Pa}$ and (e) EDAX spectrum of $0.2 \mathrm{~Pa}$ film.

observed by Sajeesh [22] for $\mathrm{SnS}$ thin films prepared by a chemical spray pyrolysis technique. As shown in figure 3b, SEM characterization of the film deposited at 0.15 Pa pressure revealed petal-shaped particles containing no pores and voids [30]. The film shown in figure $3 \mathrm{c}$ was deposited at $0.2 \mathrm{~Pa}$ pressure rate and revealed a fine spherical-shaped grains with smooth surface along with larger agglomeration of grains for the films deposited at 0.1 and $1.5 \mathrm{~Pa}$ pressure rate. Figure $3 \mathrm{~d}$ shows the film deposited at $0.25 \mathrm{~Pa}$ pressure rate with small spherical-shaped particles. The grain size increased as the carrier gas pressure increases from 0.1 to $0.2 \mathrm{~Pa}$. Thus, the increase in pressure promotes the grain growth and sintering of the film. This observed morphology of the SnS electrode displays a high surface area of the films, which can be 
a
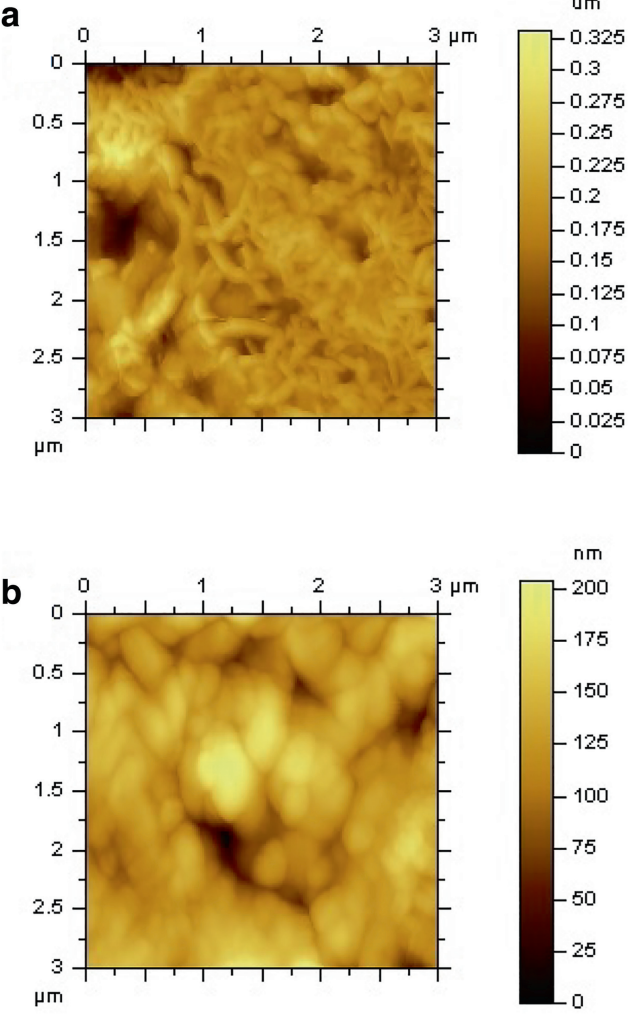

C
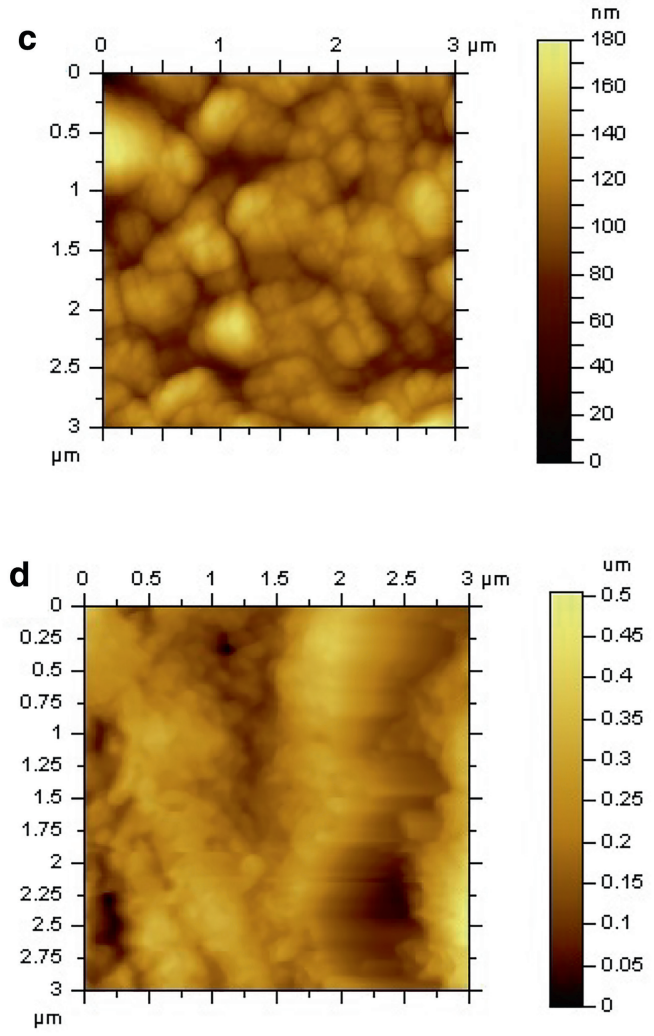
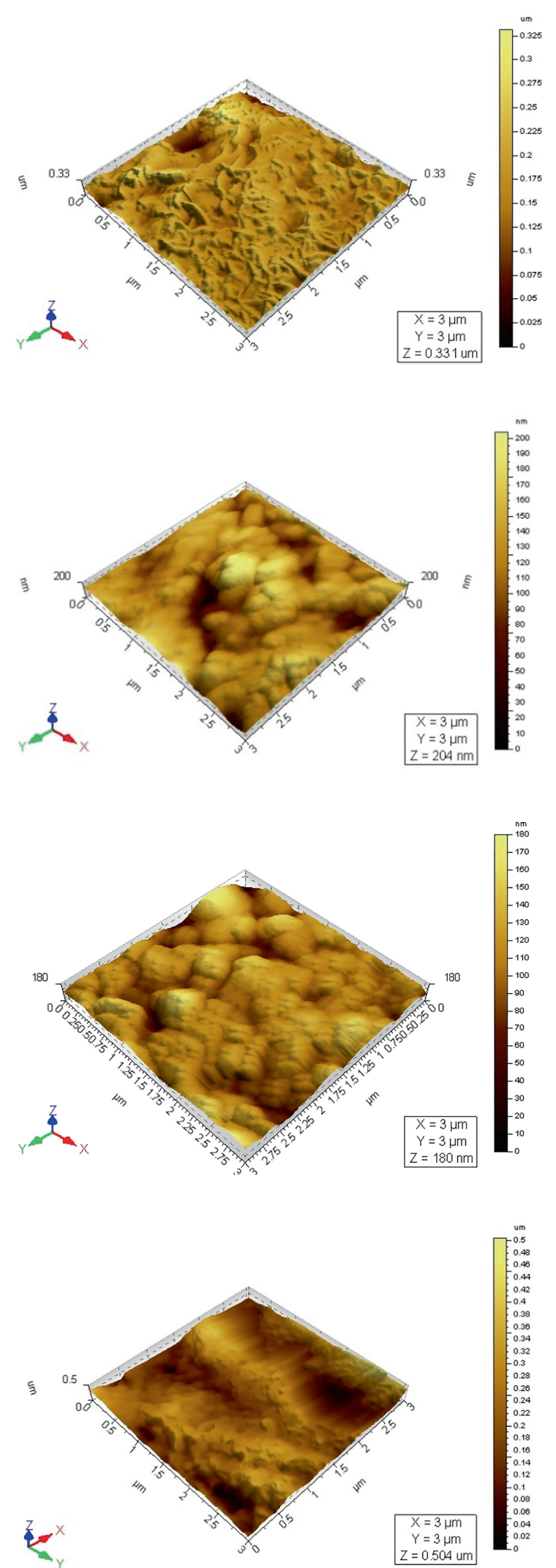

Figure 4. AFM images of SnS films deposited at different pressures: (a) 0.1, (b) 0.15, (c) 0.2 and (d) 0.25 Pa. 
advantageously used in hybrid inorganic-organic solar cells [31].

Energy-dispersive X-ray (EDX) analysis was conducted to understand the elemental composition of the film. Figure $3 \mathrm{e}$ exhibits the usual EDX spectrum of $\mathrm{SnS}$ thin film deposited using 0.2 Pa pressure rate. Atomic composition of the films derived from EDX results are shown in figure 3e. From the figure, the atomic ratio ( $\mathrm{S} / \mathrm{Sn})$ of the film shows a nearly stoichiometric ratio [32]. The extra peaks displayed in the EDX spectrum other than $\mathrm{Sn}$ and $\mathrm{S}$ peaks are due to the glass substrate (Si) and solvent of the precursor solution [33].

3.2b AFM analysis: Figure 4 represents the 2D and 3D atomic force microscopy (AFM) images of different $\mathrm{SnS}$ thin films of area $3 \mu \mathrm{m} \times 3 \mu \mathrm{m}$. These images clearly show the interdependence of mean grain size and surface roughness on the carrier gas pressure change. The surface mean grain size and roughness increase with increasing pressure. The films deposited with $0.2 \mathrm{~Pa}$ carrier gas pressure show high roughness $(34 \mathrm{~nm})$ with uniformly distributed grains. The surface roughness and mean grain size increase with increasing pressure which is due to the increase in film thickness. The root-mean-square (RMS) roughness of the film varies from 19 to $34 \mathrm{~nm}$ with the raise in carrier gas pressure from 0.1 to $0.2 \mathrm{~Pa}$. Further increase in pressure by $0.25 \mathrm{~Pa}$ reduces the roughness of the film slightly to $32 \mathrm{~nm}$. A similar effect of increase in roughness value with increase in thickness has been observed in $\mathrm{SnS}$ [29] and $\mathrm{In}_{2} \mathrm{O}_{3}$ [34] thin films. The improvement of surface roughness with pressure is again ascribed to the increase in thickness of the films. Owing to the carrier gas pressure, the grain boundary density increases due to the growth of smaller grains, which increases the height of the grains on the film surface. The RMS surface roughness and the grain size values are reported in table 3 . Therefore, it is evident that the grain size and the surface roughness changes are due to change in carrier gas pressure used for the preparation of the thin films using the NSP method.

\subsection{Optical analysis}

3.3a UV-Vis-NIR spectroscopy: The change in optical transmittance $(T)$ with the incident wavelength $(\lambda)$ for the $\mathrm{SnS}$ thin films prepared with different carrier gas pressures is shown in figure 5. It is seen that the transmittance of the film increases for higher wavelength and found to decrease

Table 3. Roughness and grain size of $\mathrm{SnS}$ films deposited at various pressures.

\begin{tabular}{lcc}
\hline Pressure $(\mathrm{Pa})$ & Roughness $(\mathrm{nm})$ & Grain size $(\mathrm{nm})$ \\
\hline 0.1 & 19 & 26 \\
0.15 & 25 & 31 \\
0.2 & 34 & 37 \\
0.25 & 30 & 32 \\
\hline
\end{tabular}

with the increase in pressure from 0.1 to $0.2 \mathrm{~Pa}$. With the additional increase in pressure $(0.25 \mathrm{~Pa})$, the transmittance also increased. In the NIR spectral region, reflection decreases during transmission, signifying that the light reduction occurred due to scattering [35]. In the absorbance spectra observed in the wavelength region of 500 to $1100 \mathrm{~nm}$ shown in figure 6 , a noticeable increase in the absorbance value of fabricated films with increase in carrier gas pressure from 0.1 to $0.2 \mathrm{~Pa}$. With further increase in the pressure, the absorption of the film is slightly decreased.

The direct optical band gap $\left(E_{\mathrm{g}}\right)$ of the film can be evaluated using the equation for the allowed absorption coefficient in a direct gap semiconductor. A plot is derived from the expression [36]

$$
(\alpha h v)^{2}=A\left(h v-E_{\mathrm{g}}\right)
$$

where $h, v$ and $\alpha$ are Planck's constant, photon frequency and the absorption coefficient, respectively, $E_{\mathrm{g}}$ is the band gap and $A$ is proportionality constant. The band gap calculated from figure 7 shows a decrease from 1.78 to $1.66 \mathrm{eV}$ for the increase in carrier gas pressure from 0.1 to $0.2 \mathrm{~Pa}$. This decrease of band gap indicates an improvement in thickness and crystallite size of the films with respect to increase in carrier gas pressure which causes a variation in the density of localized states. On further increasing the pressure $(0.25 \mathrm{~Pa})$, the band gap of the film increased to $1.73 \mathrm{eV}$. It is in close agreement with the direct allowed band gap values reported by Nair et al [37] (1.66 eV) and Jain et al [38] (1.78 eV), respectively. Specifically, the band gap depends on thickness [29]. However, from the present work, it is observed that the variation in direct band gap with respect to carrier gas pressure is due to the increase in film thickness.

The optical constants, such as refractive index $(n)$ and extinction coefficient $(k)$ of $\mathrm{SnS}$ thin films were evaluated using the following equations [39]:

$$
n^{2}=N+\left(N^{2}-n_{\mathrm{a}}^{2} n_{\mathrm{s}}^{2}\right)^{1 / 2}
$$

where

$$
N=\frac{\left(n_{\mathrm{a}}^{2}+n_{\mathrm{s}}^{2}\right)}{2}+2 n_{\mathrm{a}} n_{\mathrm{s}} T
$$

$n_{\mathrm{a}}, n_{\mathrm{s}}$ and $n$ are the refractive indices of air, substrate and the $\mathrm{SnS}$ films, respectively. $T$ is the transmittance value at a particular wavelength:

$$
k=\frac{a \lambda}{4 \pi},
$$

where $a, \lambda$ and $k$ are the absorption coefficient, wavelength and the extinction coefficient, respectively. Figure 8 shows the variation of both $n$ and $k$ of $\mathrm{SnS}$ films deposited with varying carrier gas pressure. The refractive index of the films 


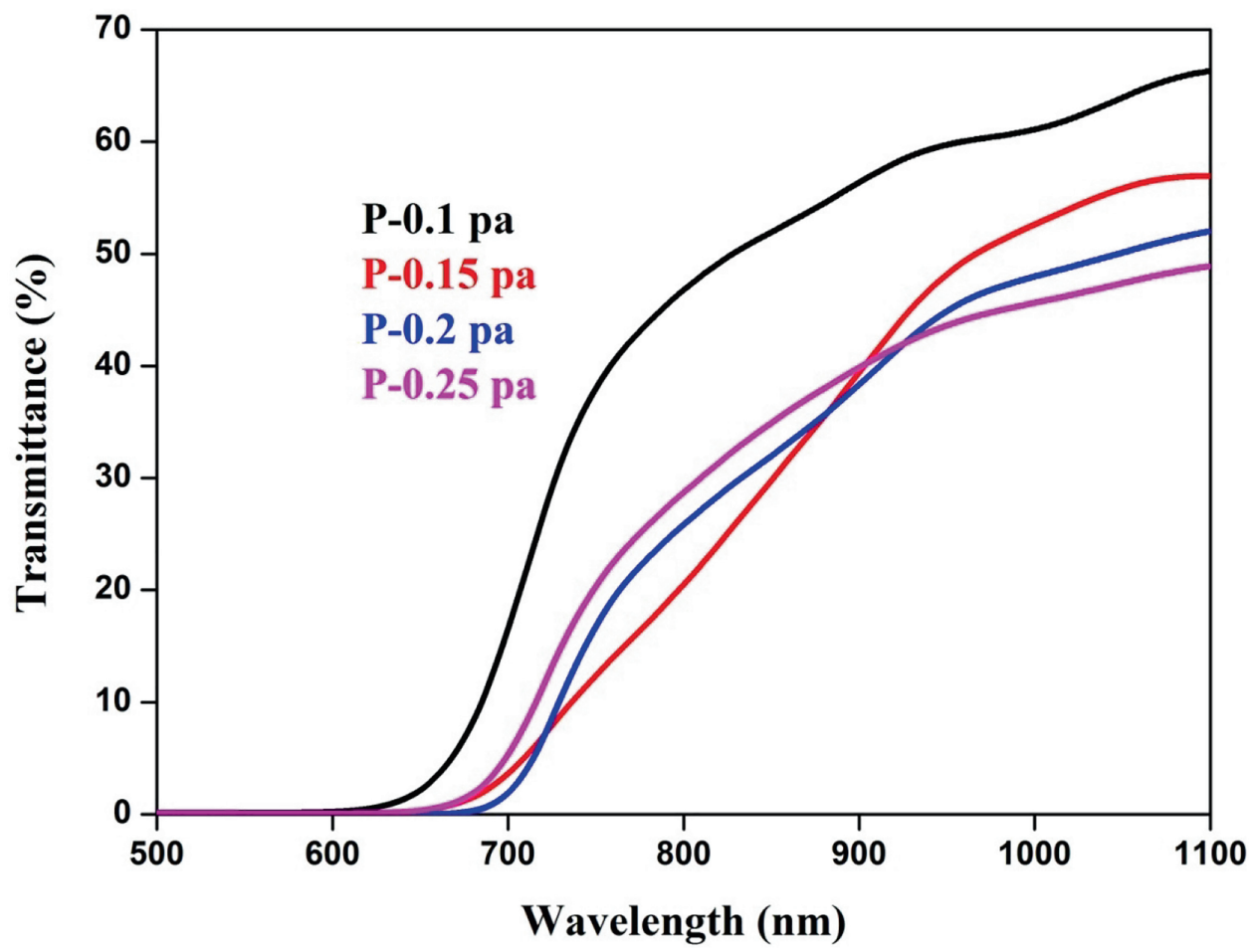

Figure 5. Transmittance spectra for $\mathrm{SnS}$ thin films prepared at different pressures.

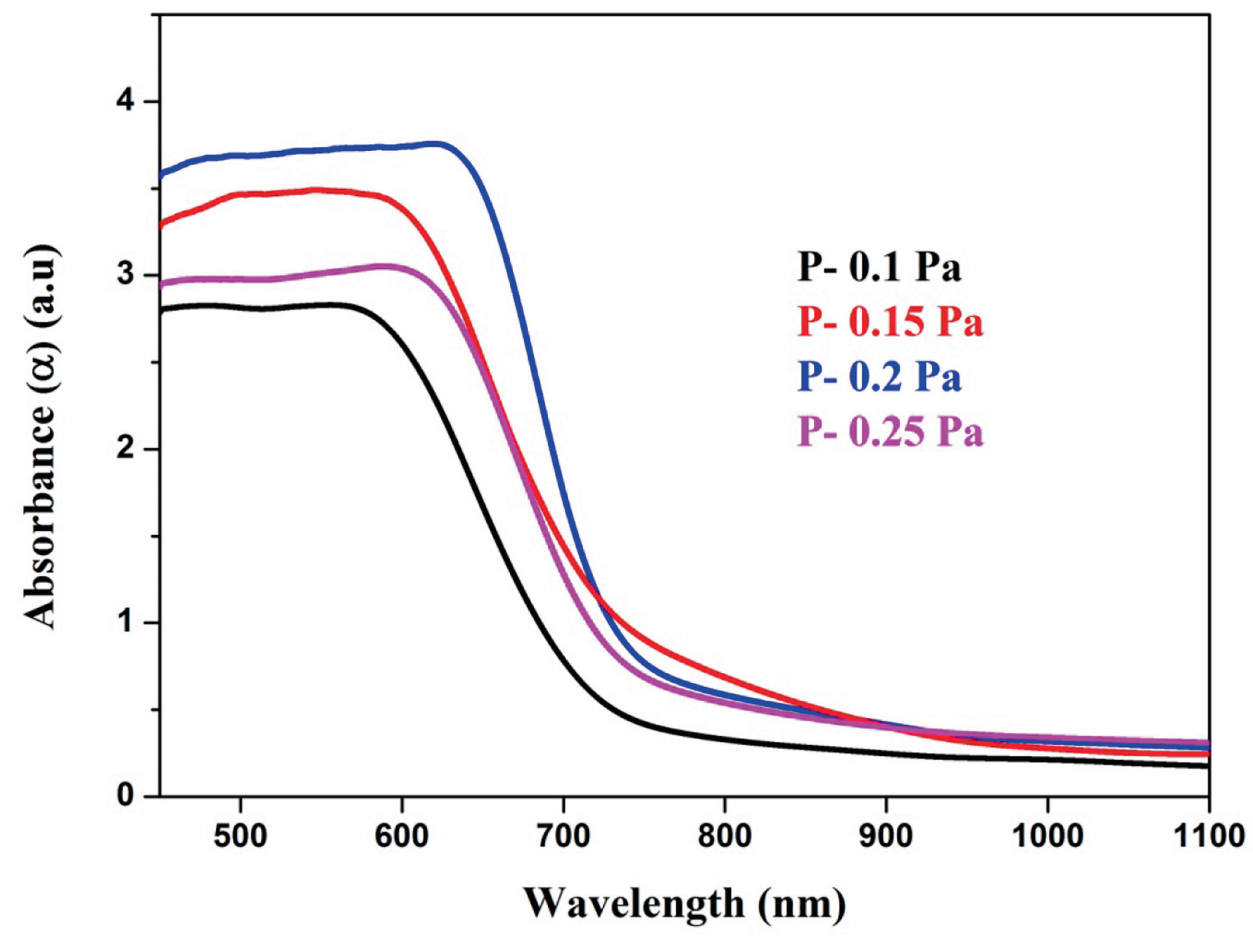

Figure 6. Absorption spectra for $\mathrm{SnS}$ thin films prepared at different pressures.

is increased with the change in carrier gas pressure from 0.1 to $0.2 \mathrm{~Pa}$ and with a further increase in pressure $(0.25 \mathrm{~Pa})$, the refractive index of the film decreased. The extinction coefficient of the films varied in the range from 0.45 to 0.61 with a change in the carrier gas pressure. The maximum extinction coefficient value obtained around 500 


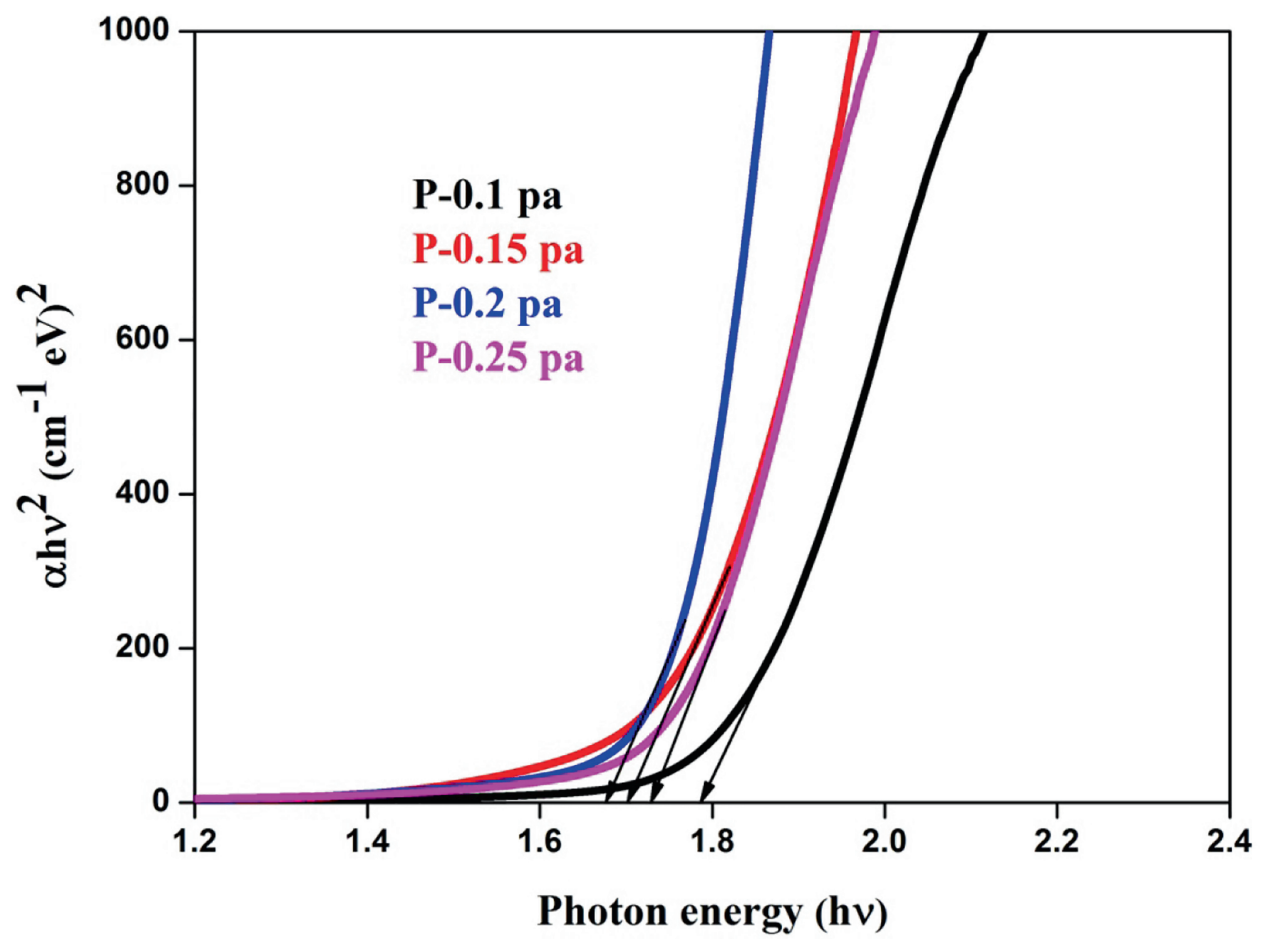

Figure 7. $(\alpha h v)^{2} v s .(h v)$ plot for $\mathrm{SnS}$ thin films prepared at different pressures.

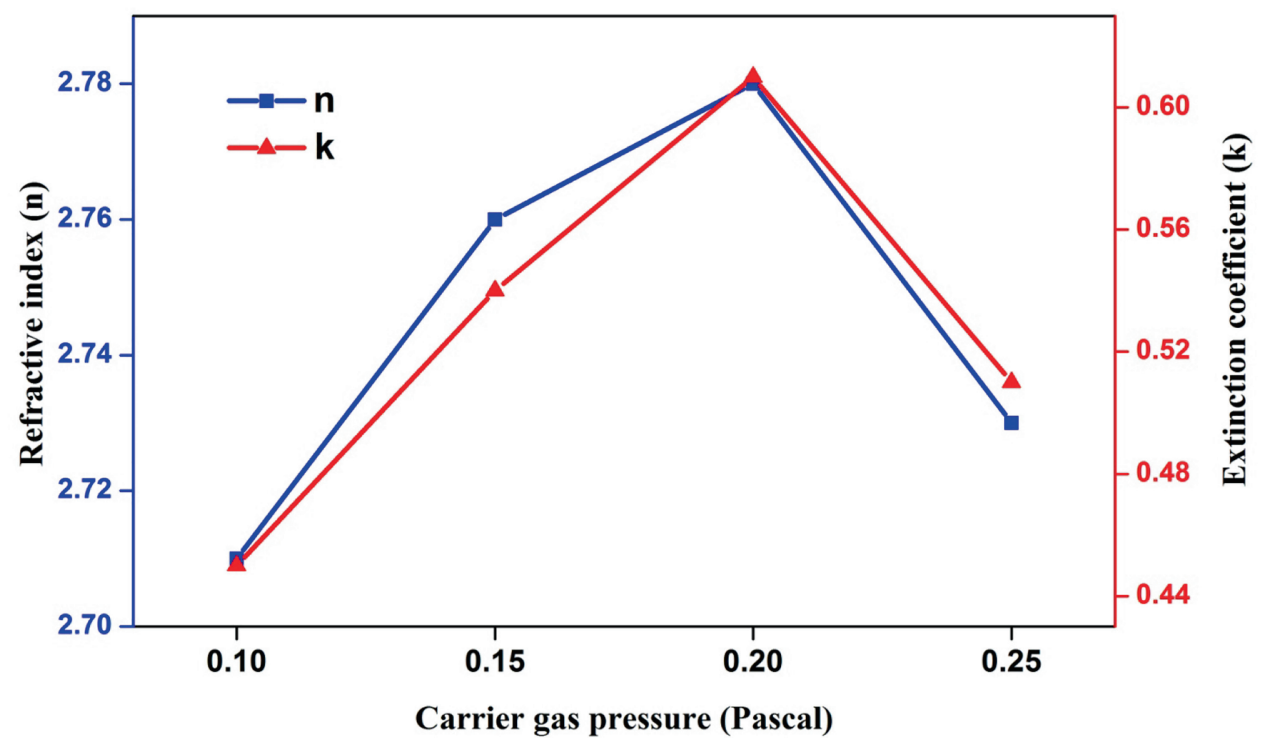

Figure 8. Refractive index $(n)$ and extinction coefficient $(k)$ of $\mathrm{SnS}$ thin films at different pressures.

$\mathrm{nm}$ is similar to the value reported by El-Nahass et al [40].

3.3b PL spectra: PL analysis is an appropriate method to find the crystalline quality and the presence of foreign elements in the material. Figure 9 displays the PL spectra of $\mathrm{SnS}$ films recorded in the wavelength range from 700 to $900 \mathrm{~nm}$ with photon excitations at $550 \mathrm{~nm}$, respectively. For excitation at $550 \mathrm{~nm}$, an intense peak was observed at about $825 \mathrm{~nm}$, corresponding to energy $\sim 1.50 \mathrm{eV}$ which may be due to near band edge emission and is a little higher than the band gap estimated from UV-Vis data. The PL spectra did not exhibit any deep level emission peaks which confirm that the prepared $\mathrm{SnS}$ thin films did not have any defects [41]. The origin of a sharp emission peak around $825 \mathrm{~nm}$ is due to the emission from vacancies and that of defects which are 


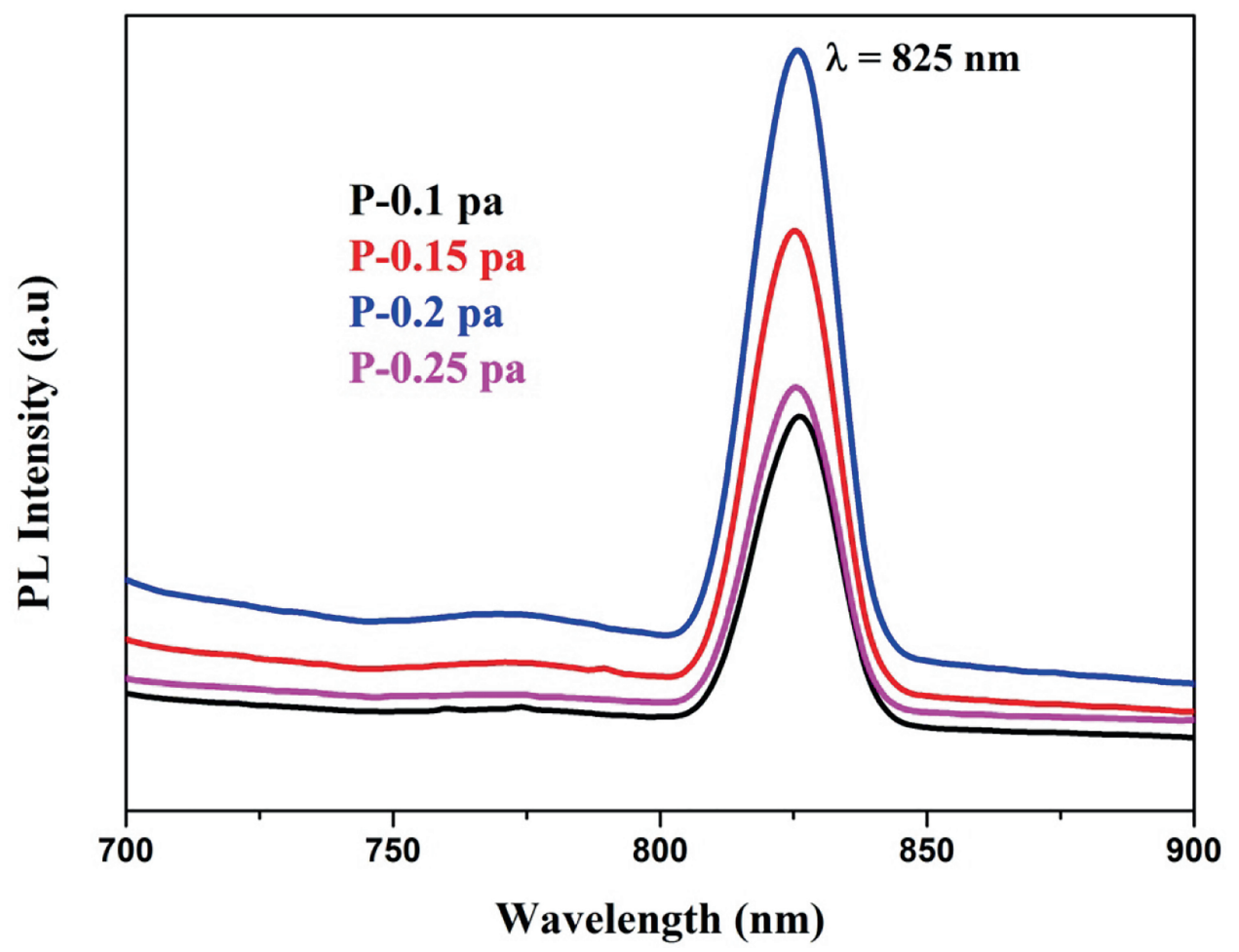

Figure 9. PL spectrum of tin sulfide $(\mathrm{SnS})$ thin films deposited at different pressures.

Table 4. Electrical properties of $\mathrm{SnS}$ films deposited at various pressures.

\begin{tabular}{lccccc}
\hline Pressure $(\mathrm{Pa})$ & $\begin{array}{c}\text { Resistivity } \\
(\Omega \mathrm{cm})\end{array}$ & $\begin{array}{c}\text { Conductivity } \\
\left(\Omega^{-1} \mathrm{~cm}^{-1}\right)\end{array}$ & $\begin{array}{c}\text { Carrier concen- } \\
\text { tration }\left(\mathrm{cm}^{-3}\right)\end{array}$ & $\begin{array}{c}\text { Mobility } \\
\left(\mathrm{cm}^{2} \mathrm{v}^{-1} \mathrm{~s}^{-1}\right)\end{array}$ & Type of conductivity \\
\hline 0.1 & 2.25 & 0.444 & $8.54 \times 10^{17}$ & 3.24 & $\mathrm{P}$ \\
0.15 & 0.512 & 1.953 & $3.15 \times 10^{18}$ & 3.87 & $\mathrm{P}$ \\
0.2 & 0.235 & 4.255 & $5.04 \times 10^{18}$ & 5.27 & $\mathrm{P}$ \\
0.25 & 0.629 & 1.589 & $2.27 \times 10^{18}$ & 4.37 & $\mathrm{P}$ \\
\hline
\end{tabular}

essential for growth, i.e., interstitial and stacking faults. All defect related bands emerge a lot higher than the band gap. Ghosh et al [42] also reports that the PL band in SnS (at $550 \mathrm{~nm}$ ) with a larger energy than the band gap. The intensity of the band edge emission peak enlarged with an increase in carrier gas pressure. This observation is in strong agreement with the XRD pattern in which the intensity of peak increased with increase in carrier gas pressure.

\section{Electrical properties of deposited $\mathrm{SnS}$ films}

\subsection{Hall measurements}

Electrical properties of $\mathrm{SnS}$ films were studied by Hall measurements using the Van der Pauw configuration. The results are summarized in table 4 . The electrical resistivity of the nebulizer spray deposited films was decreased from 2.25 to
$0.235 \Omega \mathrm{cm}$ for the increase in carrier gas pressure from 0.1 to $0.2 \mathrm{~Pa}$. On further increasing the pressure $(0.25 \mathrm{~Pa})$, the resistivity of the film slightly increased, whereas the pressure $0.2 \mathrm{~Pa}$ showed very less resistivity $0.235 \Omega \mathrm{cm}$. This change of resistivity correlates the changes in the grain size and crystallinity with the carrier gas pressure. Normally, the resistivity of thin films decreases when the film becomes thicker, due to less surface scattering of carriers and a trapping centre in the grain boundaries as the film is packed densely with thicker grains causing increase in carrier concentration [26,27]. The films deposited at $0.2 \mathrm{~Pa}$ pressure showed low resistivity of $0.235 \Omega \mathrm{cm}$ compared to other pressure rates, a higher value than in the report by Reddy et al [43]. The conductivity $4.25\left(\Omega^{-1} \mathrm{~cm}^{-1}\right)$ of the film deposited at $0.2 \mathrm{~Pa}$ pressure is higher than the value reported by Devika et al [44] for thermal evaporation technique. This higher conductivity is attributed to the highly crystalline and pure phase of the $\mathrm{SnS}$ film, without any traces of Magneli phases. All the films possess 


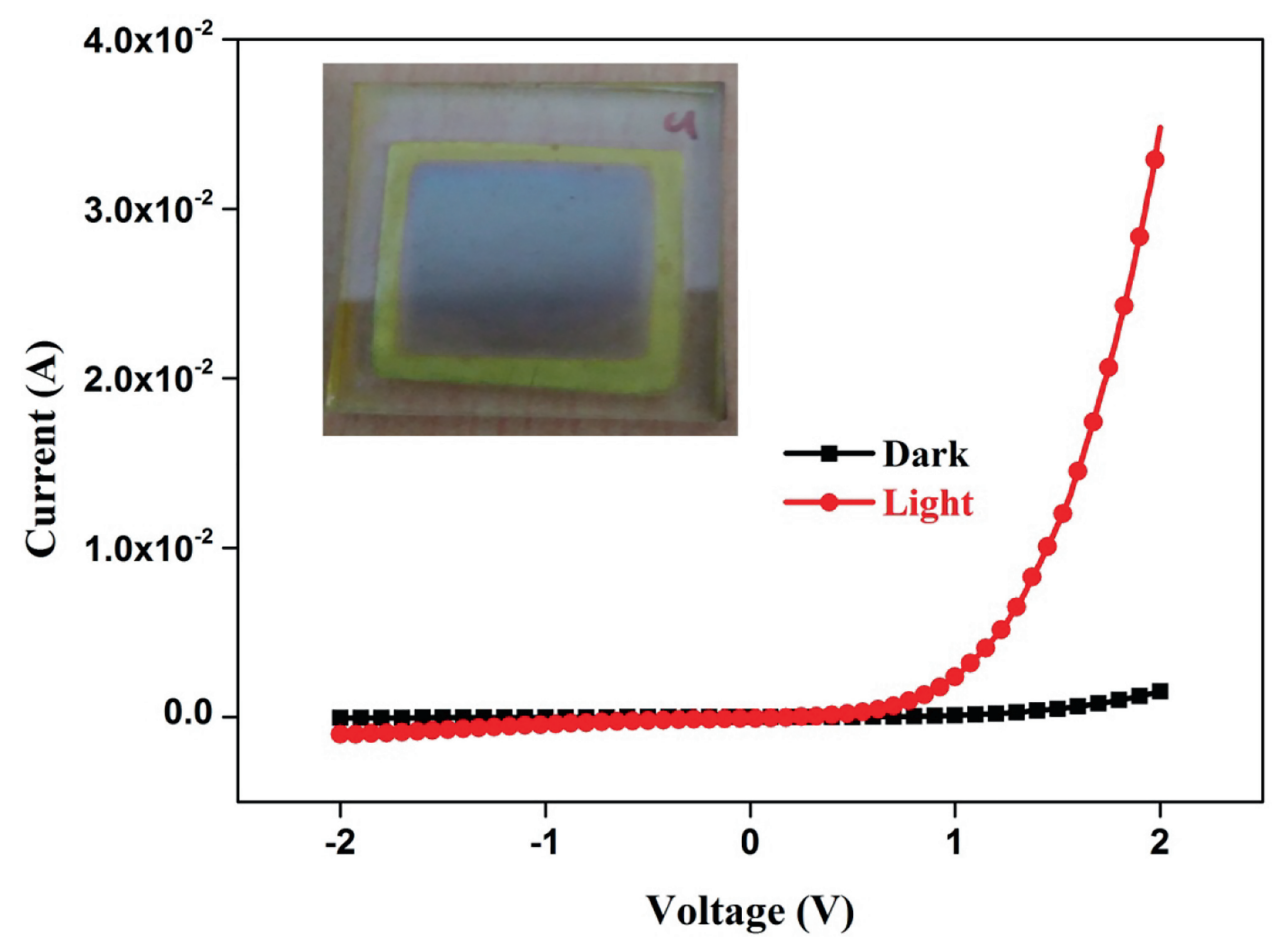

Figure 10. $I-V$ characteristics of $\mathrm{FTO} / \mathrm{CdS} / \mathrm{SnS}$ heterostructures for pressure $0.2 \mathrm{~Pa}$. The inset shows the $\mathrm{CdS} / \mathrm{SnS}$ heterostructure sample.

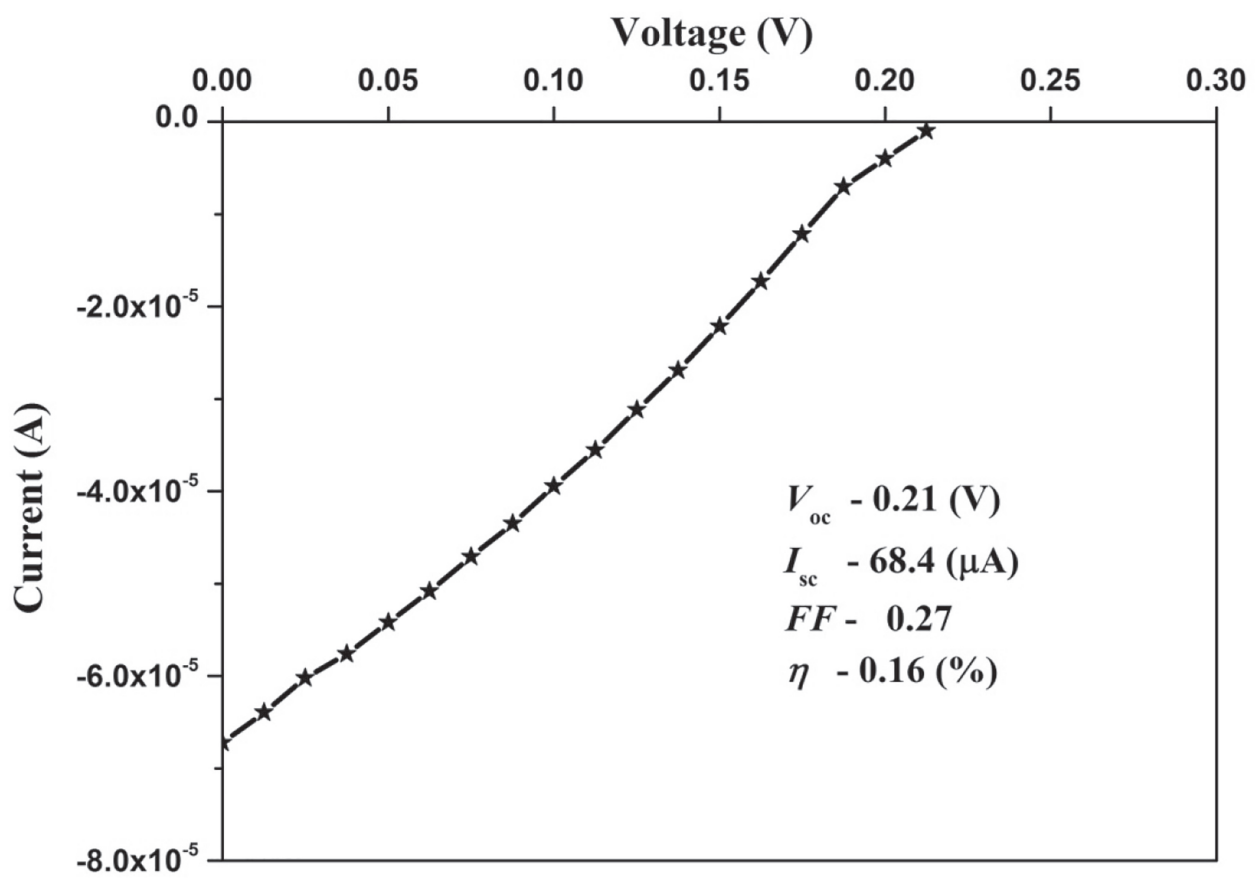

Figure 11. Illuminated $I-V$ characteristics of $\mathrm{FTO} / \mathrm{CdS} / \mathrm{SnS}$ heterostructure film.

p-type conductivity which was confirmed from the Hall measurement. The increase in carrier gas pressure significantly increases the carrier concentration from the order of $10^{17}$ to $10^{18}$ due to the increase in the film thickness [6].
The increase in carrier concentration is due to the crystalline improvement of the films as indicated by XRD results. A similar variation of Hall mobility and carrier density is also reported for the change of precursor concentration variation 
[45] and substrate temperature variation [20] in spray pyrolysis preparation of $\mathrm{SnS}$ films.

\subsection{I-V characteristics of $n-C d S / p-S n S$ heterostructure}

The SnS-based PV cells were fabricated with 0.2 Pa pressure on nebulizer spray deposited $\mathrm{CdS} / \mathrm{SnS}$ over FTO-coated glass substrate. The surface of the $\mathrm{CdS} / \mathrm{SnS}$ film and the back of the FTO substrate are shown (inset of figure 10) respectively. The $I-V$ characteristics of $\mathrm{FTO} / \mathrm{CdS} / \mathrm{SnS}$ heterostructures in the dark and under illumination are shown in figure 10. The structures present high rectification properties under the dark and light conditions. However, very strong PV response was detected for the sample despite several attempts. Due to minority carriers, a minimum value of current will be produced in the dark, however, after illumination, the current value increases and starts the PV process and due to charge carriers created by incident photons, the current is affected. Thin film heterojunction PV device with the arrangement FTO/n-CdS/p-SnS was primed by nebulizer spray deposited $\mathrm{CdS}$ and $\mathrm{SnS}$ with active area about $0.5 \mathrm{~cm}^{2}$. Figure 11 depicts the early outcomes on illuminated $I-V$ nature of FTO/n-CdS/p-SnS PV cell.

The fill factor $(\mathrm{FF})$ is evaluated from the below equation [46]:

$$
\mathrm{FF}=V_{\mathrm{m}} \times I_{\mathrm{m}} / V_{\mathrm{oc}} \times I_{\mathrm{sc}}
$$

where the $V_{\mathrm{m}}$ and $I_{\mathrm{m}}$ are the values of maximum voltage and maximum current, respectively. The efficiency $\eta(\%)$ is calculated from the below equation:

$$
\eta=V_{\mathrm{oc}} \times I_{\mathrm{sc}} \times \mathrm{FF} \times 100 / P_{\text {input }} .
$$

The series resistance $\left(R_{\mathrm{S}}\right)$ and shunt resistance $\left(R_{\mathrm{sh}}\right)$ are calculated using the following equations:

$$
\begin{gathered}
(\mathrm{d} I / \mathrm{d} V)_{I=0}=\left(1 / R_{\mathrm{s}}\right), \\
(\mathrm{d} I / \mathrm{d} V)_{v=0}=\left(1 / R_{\mathrm{sh}}\right),
\end{gathered}
$$

where $P_{\text {input }}$ is the input light energy. The FF and $\eta$ were also evaluated using standard equations. In the present study, a short circuit current density of $68.4 \mu \mathrm{A}$, an open circuit voltage of $0.21 \mathrm{~V}$, an FF of 0.27 and a conversion efficiency of about $0.16 \%$ were observed when illuminated by a source of light of about $100 \mathrm{~mW} \mathrm{~cm}^{-2}$. Thus, the PV effects of the $\mathrm{CdS} / \mathrm{SnS}$ cells are much weaker than the $\mathrm{CdS} / \mathrm{SnS}$ cells by spray pyrolysis technique [47]. The series and shunt resistances are calculated as 1.6 and $17 \mathrm{k} \Omega$, respectively. Moreover, a thorough study on various key properties and cell characteristics of $\mathrm{FTO} / \mathrm{n}-\mathrm{CdS} / \mathrm{p}-\mathrm{SnS}$ devices are in progress.

\section{Conclusion}

Tin sulphide layers were grown on a glass substrate by the NSP method at $350^{\circ} \mathrm{C}$ by varying the carrier gas pressure from 0.1 to $0.25 \mathrm{~Pa}$. The grown $\mathrm{SnS}$ thin films are single phase, showing an orthorhombic structure with high intense (210) and (111) peaks as preferred orientation. The crystallite size of the $\mathrm{SnS}$ thin films is about $33 \mathrm{~nm}$ for the pressure of 0.2 Pa. Raman analysis showed high intense peaks at 95, 165,191 and $219 \mathrm{~cm}^{-1}$ confirming the formation of SnS thin films. The extinction coefficient of the films varied in the range of $0.45-0.61$ depending upon pressure variation. Both optical transmittance and energy band gap decreased with the increase in carrier gas pressure. The films showed a band gap in the range of $1.78-1.66 \mathrm{eV}$ for the variation of pressure. The surface morphological study showed that the carrier gas pressure variation changes the grain size and shape of the grains. AFM images indicate that regular, homogeneous surface and surface roughness were obtained under these conditions. The samples deposited with the carrier gas pressure of $0.2 \mathrm{~Pa}$ exhibited a low resistivity of $0.235 \Omega \mathrm{cm}$ compared to other samples. From the electrical studies, a solar cell of the type FTO/n-CdS/p-SnS was fabricated and a strong $\mathrm{PV}$ response was detected for the $0.2 \mathrm{~Pa}$ pressure sample.

\section{Acknowledgements}

We wish to express our sincere thanks to the Department of Science and Technology, New Delhi, India, for financial assistance for the work by the project number SB/FTP/PS$131 / 2013$.

\section{References}

[1] Sall T, Soucase B M, Mollar M and Sans J A 2016 J. Electron. Mater. 461714

[2] Ogah O E, Zoppi G, Forbes I and Miles R W 2009 Thin Solid Films $\mathbf{5 1 7} 2485$

[3] Mani P, Manikandan K and Joseph Prince J 2016 J. Mater. Sci.: Mater. Electron. 279255

[4] Gomez A, Martinez H, Calixto-Rodriguez M, Avellaneda D, Reyes P G and Flores O 2013 J. Mater. Sci. Eng. B 3352

[5] Santhosh Kumar K, Gowri Manohari A, Dhana Pandian S and Mahalingam T 2014 Mater. Lett. 131167

[6] Ghosh B, Bhattacharjee R, Banerjee P and Das S 2011 Appl. Surf. Sci. 2573670

[7] Ristov M, Sinadinovski G, Mitreski M and Ristova M 2001 Sol. Energy Mater. Sol. Cells 6917

[8] Ghosh B, Das M, Banerjee P and Das S 2009 Semicond. Sci. Technol. 24025024

[9] Vidal J, Lany S, Avezac M, Zunger A, Zakutayev A, Francis J et al 2012 Appl. Phys. Lett. 100032104

[10] Louise S Price, Ivan P Parkin, Amanda Hardy M E and Robin Clark J H 1999 Chem. Mater. 111792 
[11] Ramakrishna Reddy K T, Purandar Reddy P, Miles R W and Datta P K 2001 Opt. Mater. 17295

[12] Chalapathi U, Poornaprakash B and Si-Hyun P, 2016 Sol. Energy 139238

[13] Henry J, Mohanraj K, Kannan S, Barathan S and Sivakumar G 2013 Eur. Phys. J. Appl. Phys. 6110301

[14] Miles R W, Ogah O E, Zoppi G and Forbes I 2009 Thin Solid Films $\mathbf{5 1 7} 4702$

[15] Ghazali A, Zainal Z, Hussein M Z and Kassim A 1998 Sol. Energy Mater. Sol. Cells 55237

[16] Ramakrishna Reddy K T, Purandhara Reddy P, Datta P K and Miles R W 2002 Thin Solid Films 404116

[17] Sinsermsuksakul P, Heo J, Noh W, Hock A S and Gordon R G 2011 Adv. Energy Mater. 11116

[18] Abdelrahman A E, Yunus W M M and Arof A K 2012 J. NonCryst. Solids 3581447

[19] Reddy N K and Ramakrishna Reddy K T 1998 Thin Solid Films 3254

[20] Guneri E, Ulutas C, Kirmizigul F, Altindemir G, Gode F and Gumus C 2010 Appl. Surf. Sci. 2571189

[21] Santhosh Kumar K, Manoharan C, Dhana Pandian S, Gowri Manohari A and Mahalingam T 2014 Optik 1253996

[22] Sajeesh T H, Jinesh K B, Sudha Kartha C and Vijayakumar K P 2012 Appl. Surf. Sci. 2586870

[23] Voznyi A, Kosyak V, Opanasyuk A, Tirkusova N, Grase L, Medvids A et al 2016 Mater. Chem. Phys. 1731

[24] Opanasyuk A S, Kurbatov D I, Kosyak V V, Kshniakina S I and Danilchenko S N 2012 Crystallogr. Rep. 57927

[25] Hadjiev V G, De D, Peng H B, Manongdo J and Guloy A M 2013 Phys. Rev. B 87104302

[26] Kherchachi I B, Saidi H, Attaf A, Attaf N, Bouhdjar A, Bendjdidi $\mathrm{H}$ et al 2016 Optik 1274043

[27] Sinsermsuksakul P, Heo J Y, Noh W, Hock A S and Gordon R G 2011 Adv. Energy Mater. 11116

[28] Reddy N K, Devika M and Gunasekhar K R 2014 Thin Solid Films $\mathbf{5 5 8} 326$
[29] Srinivasa Reddy T and Santhosh Kumar M C 2016 RSC Adv. 695680

[30] Zimin S P, Gorlachev E S, Amirov I I, Naumov V V, Dubov G A, Gremenok V F et al 2014 Semicond. Sci. Technol. 29 015009

[31] Rath T, Gury L, Sanchez-Molina I, Martinez L and Haque S A 2015 Chem. Commun. 5110198

[32] Sall T, Mollar M and Mari B 2016 J. Mater. Sci. 517607

[33] Xu J, Yang Y and Xie Z 2014 Chalcogenide Lett. 11485

[34] Majeed Khan M A and Khan W 2016 J. Electron. Mater. 8 4453

[35] Selim M S, Gouda M E, El-Shaarawy M G, Salem A M and Abd El-Ghany W A 2013 Thin Solid Films 527164

[36] Cheng S, He Y, Chen G, Cho E-C and Conibeer G 2008 Surf. Coat. Technol. 2026070

[37] Nair P K, Garcia-Angelmo A R and Nair M T S 2016 Phys. Status Solidi A 213170

[38] Jain P and Arun P 2013 Thin Solid Films 548241

[39] Ramakrishna Reddy K T, Sreedevi G and Miles R W 2013 J. Mater. Sci. Eng. A 3182

[40] El-Nahass M M, Zeyada H M, Aziz M S and El-Ghamaz N A 2002 Opt. Mater. 20159

[41] Kiruthigaa G, Manoharan C, Bououdina M, Ramalingam S and Raju C 2015 Solid State Sci. 4432

[42] Ghosh B, Das M, Banerjee P and Das S 2008 Appl. Surf. Sci. 2546436

[43] Reddy N K and Ramakrishna Reddy K T 2005 Solid-State Electron. 49902

[44] Devika M, Reddy N K, Ramesh K, Ganesan V, Gopal E S R and Ramakrishna Reddy K T 2006 Appl. Surf. Sci. 2531673

[45] Sajeesh T H, Anita Warrier R, Sudha Kartha C and Vijayakumar K P 2010 Thin Solid Films 5184370

[46] Barote M A, Yadav A A, Chavan T V and Masumdar E U 2011 Digest J. Nanomater. Biostruct. 6979

[47] Ramakrishna Reddy K T, Reddy N K and Miles R W 2006 Sol. Energy Mater. Sol. Cells 903041 